\title{
Isolated cases or widespread practice? The occurrence of sharing managers in Swedish working life
}

\author{
Marianne Döös ${ }^{1 *} \cdot$ Tomas Backström ${ }^{2} \cdot$ Marika Melin $^{3} \cdot$ Lena Wilhelmson $^{2}$ \\ ${ }^{I}$ Department of Education, Stockholm University, Stockholm, Sweden \\ ${ }^{2}$ Innovation, Design and Engineering, Mälardalen University, Eskilstuna, Sweden \\ ${ }^{3}$ Department of Psychology, Stockholm University, Stockholm, Sweden
}

Received: 14 February 2012

Revised: 15 September 2012

Accepted: 16 October 2012

\begin{abstract}
In investigating whether shared leadership can be tracked on a work-life level, this study aims to contribute knowledge about how common shared leadership is among managers in Sweden. A search was made for equal assumption of responsibilities and, specifically, for joint leadership, i.e. a formal mandate for decision-making affecting the full range of responsibilities attaching to the managerial post. The results show that shared leadership is tracked on a work-life level, and that the most far-reaching form joint leadership was found among $5 \%$ of the managers. Thus, the phenomenon cannot be ignored as anecdotal. This adds relevance to influencing perceptions of leadership towards more pluralism, in which questions of leadership naturally incorporate more interactive variations than does the hitherto accepted theory of singular leadership.
\end{abstract}

Keywords: joint leadership, manager, managerial post, national survey, work organization

JEL Classification Codes: M00, M10

\section{Introduction}

The idea of leadership in today's organisations rests on the notion that leadership in a managerial position should be filled by only one person. Objections to a more collective and

*Corresponding author. E-mail: marianne.doos@edu.su.se.

Citation: Döös, M., T. Backström, M. Melin and L. Wilhelmson (2012) Isolated cases or widespread practice? The occurrence of sharing managers in Swedish working life, Economics and Business Letters, 1(3), 23-36. 
shared leadership are based on the idea that effective leadership can only be exercised by a single person. This despite the fact that, in the workplace, it may be considered common knowledge that managers' exercise of leadership is associated with a number of difficulties and limitations. However, leadership has during the last decade in research literature been described as collective and relational to an increasing extent (Bolden, 2011; Ensley, Hmieleski \& Pearce, 2006; Thorpe, Gold, \& Lawler, 2011). The interest in leadership as a shared and distributed phenomenon is part of this trend, and recurrently discussed in recent leadership literature. The sharing of leadership responsibility takes varying forms, formal as well as informal. Furthermore, managerial positions can be organized differently if leadership is seen as distributed among two or three people sharing the position on an equal and full-time basis (Döös, 2010). Such organizing can be seen as a special case of shared leadership (Pearce \& Conger, 2003) where power is distributed within a set of two or three managers.

Organisations as well as managers themselves have raised the notion of sharing on the managerial level as a possible means of remedying taxing work situations in Swedish working life, especially for low and middle management. Studies have shown that high proportions of managers find the management work too strenuous. This is related to the need to cope with flattened hierarchies, the amalgamation of departments, larger numbers of subordinates, and wider operational fields that are characteristic of working life in Sweden (Hildingsson \& Krafft, 2003). Holmberg and Tyrstrup (2010) describe how leadership is conducted in the everyday context where managers encounter problematic situations in a never-ceasing flow of events. The wish to share leadership may be connected to such contemporary work situations for managers.

Leadership research and literature stress that organisations, which practise management by objectives and, thus, strive toward employee responsibility and participatory influence, call for a different form of control and leadership (Marion \& Uhl-Bien, 2002; Streatfield, 2001). Some studies have also found typical attributes of a Swedish leadership style, culture specific combinations of ideas regarding, for example, participative leader characteristics and management style (Holmberg \& Åkerblom, 2006; Isaksson, 2008).

Examples of shared leadership among managers have been identified and conceptualised in our own case studies (Döös, 2010; Döös, Wilhelmson, \& Hemborg, 2003a). Qualitative studies of managers sharing in the form of "joint leadership"1 give voice to effects concerned with improving the profitability and quality of operational performance (Döös, et al., 2003a; Wilhelmson \& Döös, 2009). Work becomes more fun and more gratifying (Döös, et al., 2003a; Wilhelmson, 2006; Wilhelmson \& Döös, 2009), which makes the managers able to achieve a more sustainable situation, and also become more accessible to their employees (Wilhelmson, et al., 2006). Interestingly enough, sharing managers that we studied did not mention the feeling of taxing work situations described above. Similar positive results are reported by other cases of sharing in Sweden (Holmberg \& Söderlind, 2004; Karlsson \& Rubensson, 2001; Sjöberg, 2000). The risk of such cases merely being isolated examples has fuelled the current authors' interest in trying to track shared leadership on a work-life level. Hence, this is in the scope of this paper. To the best of our knowledge, there has before the present study been a complete lack of published research-based figures concerning the occurrence of shared leadership among managers.

\section{Aim and delimitations}

The limitations of singular leadership make it reasonable to examine alternative models and forms, and to contribute knowledge about to what extent managers work in formal and

1 "Samledarskap" in Swedish. 
informal sharing. Previous case studies identifying sharing of leadership among managers have in Sweden met with reactions from both the research community and practitioners. Reactions that tended to reduce its potential indicated that it is not a widespread phenomenon. Rather, it has been believed to be a rare occurrence, perhaps only in specific workplaces, and preferably among women. Therefore, this study investigates whether the occurrence of shared leadership can be tracked on a level of working life in Sweden, highlighting whether sharing of leadership does exist to a measurable extent among managers. Thus, the aim is to contribute knowledge about the frequency of shared leadership in general among managers, and, more specific also in the subform of formal joint leadership. Partial topics of enquiry in our study concern variations of occurrence and forms related to factors as sector, industry, workplace size, managerial level, and gender. The underlying reason for our interest in quantitatively tracking the shared leadership phenomenon is the aforementioned identification of cases of shared leadership among managers, and also the potential with co-leading in international leadership literature (e.g. Greenberg-Walt \& Robertson, 2001; Gronn \& Hamilton, 2004; Heenan \& Bennis, 1999; Troiano, 1999).

Shared leadership was in the interview questionnaire of the current empirical study defined as "assuming collective responsibility for an entire managerial area". According to previous studies (Döös \& Wilhelmson, 2003), shared leadership could take the form of either one managerial position being shared between two $^{2}$ people on the basis of a formal decision, or that of two persons in actual practice sharing one person's managerial responsibility (i.e. without any formal decision by the organization).

\section{Theoretical frame of reference}

Leadership theory is mainly based upon the notion that one managerial position equals one manager. The contemporary interest in transformational and charismatic leadership rests upon this notion. Alvesson and Sveningsson (2003) state that leadership is usually framed in visionary and heroic terms:

... it is the leader's ability to address (by talking and persuading) the many through the use of charisma, symbols, and other strongly emotional devices, the ambition being to arouse and encourage people to embark upon organizational projects. [...] Leadership is about the manager/leader being active and powerful. The leader acts, the follower responds. (ibid. pp. 1435-1436)

In work on developmental leadership Larsson et al. (2003) support the traditional representation of favorable leadership (see Figure 1) when relating leadership styles to organizational result and individual development. The model describes a leadership style development where Bass' and Burns' transformational ${ }^{3}$ leadership is depicted as the most favorable. Here, this is regarded as one out of many examples where the underlying assumption of singularity is implicit and does not investigate into how leadership in managerial positions is organized.

\footnotetext{
${ }^{2}$ In both cases, sharing can sometimes be among more than two persons.

3 In Larsson's terms “developmental".
} 
Figure 1. Traditional leadership style model based upon Larsson et al. (2003)

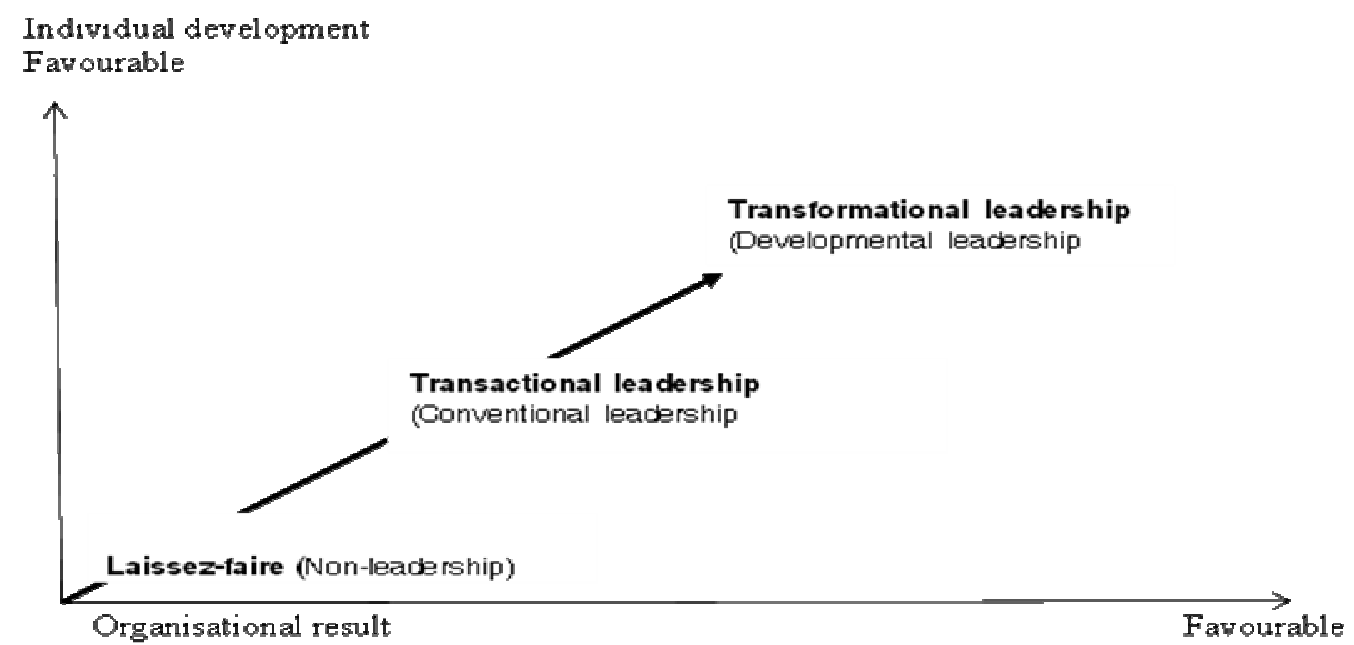

In contrast, our research rests upon organizational pedagogics with a specific interest in cooperation processes and organizational learning (Döös, 2007; Döös \& Wilhelmson, 2011). To study leadership through this learning theory lens means to consider the continuous organizing of conditions for learning and competence development in everyday life within organizations. This interest set our eyes on how leadership in managerial positions can be organized as duo or trio partnerships. In the Swedish context, characterised by a workplace culture with low hierarchical distances (Holmberg \& Åkerblom, 2007), such organizing departs from ideas of charismatic transformational leaders (Döös, Wilhelmson, \& Hemborg, 2003b). Instead, sharing among managers seems connected to the post-heroic bent that Alvesson and Sveningsson (2003) have described within the narrative of leadership as singular.

According to Yukl (2009) new conceptual frameworks are needed. In his widely used definition of leadership Yukl opens up for collectivity when stressing "the success of collective effort by members of a group" (Yukl, 2002, p. 7) as he defines leadership without connecting it to a single individual:

The process of influencing others to understand and agree about what needs to be done and how it can be done effectively, and the process of facilitating individual and collective efforts to accomplish the shared objectives. (ibid., p. 7).

Shared leadership has been described as an innovation of our time; in fact, it is a phenomenon extending far back in history. Sally (2002) and Wistrand (1978) describe that the ancient Romans were already practicing shared leadership. Specifically, Republican Rome's two highest officers of state - the consuls - shared power at the apex of a power-sharing system in which every official must have a colleague with equal authority (Sally, 2002; Wistrand, 1978).

Shared leadership within a managerial position can be theoretically described as an offshoot within hierarchical work organization theory and, from such a point of departure, can be linked to issues concerning vertical power and influence processes between managers and their subordinates. The phenomenon is also seen as part of theories concerning the wider distribution of leadership among the members of an organization (Pearce \& Conger, 2003). Distribution can be noted in how sharing managers put effort into empowering co-workers (Erlingsdóttir, 2010), as well as in the work processes and in how tasks are shared within the leadership (Döös, 2010). As Pearce (2004) states, the cases where managers share one managerial position implies a kind of cooperation that "entails a simultaneous, ongoing, 
mutual influence process within a team that is characterized by "serial emergence"' (p. 48) of the leaders. Thus, they lead each other as well as the subordinates. Vine et al. (2008) suggest a continuum where Heenan and Bennis' (1999) co-leading partnerships among top leaders is placed at the more conservative end. They place shared leadership further down the continuum, where the responsibility to lead a group rotates among its members depending upon the demands of the situation. The distributed leadership is placed even further down the continuum, and is defined as the team leading "work collectively and independently of formal leaders" (Vine, et al., 2008, p. 341).

Recent research concerning shared leadership on the low and middle management level in Sweden (Erlingsdóttir, 2010; Rosengren, 2008; Wilhelmson, 2006) contrasts with how the phenomenon has been studied elsewhere. The interest for leadership sharing has in other countries largely focused upon top management, at the apex of the leadership hierarchy (cf. Alvarez, Svejenova, \& Vives, 2007; Ensley, et al., 2006; Greenberg-Walt \& Robertson, 2001; Heenan \& Bennis, 1999; Troiano, 1999). The sharing of such top positions is described as transitory and suitable when companies merge (Greenberg-Walt \& Robertson, 2001; O'Toole, Galbraith, \& Lawler, 2002; Troiano, 1999). In contrast, sharing among managers in Sweden is thought of as part of a post-heroic development in leadership research; and is portrayed as long term trust-based managerial cooperation (Döös \& Wilhelmson, 2003; Wilhelmson, 2006; Wilhelmson, et al., 2006). Such stable sharing has been identified in case studies (Döös, et al., 2003a; Wilhelmson, et al., 2006), and has been attached to strength in bringing about organizational change (Erlingsdóttir, 2010; Rosengren, 2008; Wilhelmson \& Döös, 2009).

Part of the current authors' previous undertaking has been to conceptualise and differentiate the various subforms of shared leadership among managers in order to better understand and identify managerial sharing of leadership. See Table 1. In line with the aim of this paper to contribute knowledge about the frequency of shared leadership both in general, and in the subform of formal joint leadership the latter is here presented.

Table 1. Four subforms of shared leadership among managers

(Döös, 2010; Döös and Wilhelmson, 2003).

\begin{tabular}{l|ll}
\hline \hline Joint vs. Divided & Work tasks: Jointly & Work tasks: Divided \\
\hline \hline $\begin{array}{l}\text { Responsibility/authority } \\
\text { jointly }\end{array}$ & Joint leadership & $\begin{array}{l}\text { Functionally shared } \\
\text { leadership }\end{array}$ \\
$\begin{array}{l}\text { Responsibility/authority } \\
\text { divided }\end{array}$ & Shadow leadership & $\begin{array}{l}\text { Other forms (e.g. } \\
\text { matrix leadership, } \\
\text { rotating leadership) }\end{array}$ \\
\hline \hline
\end{tabular}

In order to depict how sharing is formed within a leadership pair the two aspects task and responsibility were related to having them in common or splitting them up. Combining joint work tasks and joint responsibility/authority of sharing managers with divided work tasks and divided responsibility/authority gives four forms where joint leadership comes out as the most far-reaching in being equals in enacting leaderships on the basis of sharing a managerial position (Döös \& Wilhelmson, 2003; Wilhelmson, 2006). Joint leadership is characterised by two equal managers leading their organizational unit on the basis of pooling work tasks, having joint authority and staff, and collectively taking an overall responsibility for a managerial area, both in practice and by the organization's formal decision. Neither is subordinate in the core of the joint leadership phenomenon. The joint leadership form is the kind of sharing that differs the most from traditional singular leadership. 
The joint leadership form has also been found to bring about transformative learning among the involved managers (Wilhelmson, 2006). Transformative learning offers the possibility of a deepened learning process in daily work (ibid.) and in a competence-bearing relationship (Döös, 2007) where core values and ways of acting are openly shared and critically reflected upon.

For transformative learning to occur in joint leadership, safety and trust, together with openness, and a habit of questioning and critically reflecting on things, seem to be important. Having equal power, and complementary competencies and interests, also seems important. Dialogue within management is something solitary leaders never get access to. (Wilhelmson, 2006, p. 505).

\section{Methods}

Previous qualitative studies of shared leadership pointed toward a need to know if such way of working was a quantitatively widespread practice or merely isolated cases. The study was a survey performed through brief highly structured telephone interviews with managers at a representative sample of workplaces in Sweden, both in the public and private sectors. The study proceeded in two stages: (1) an initial screening for the purpose of mapping workplaces with at least ten employees with respect to the number of managers on three different managerial levels (top, middle, low) and to estimate workplace sector (public/private) and workplace size, and (2) interviews with a random sample of managers in these workplaces. The screening indicated a total of 41843 workplaces in the private sector and 26096 in the public sector, with a total of approx. 350,000 managers. Private and public workplaces were divided into six groups for the screening: small (10-49 employees), medium (50-199), large (200-). The total number of managers estimated through the screening was divided into 18 groups: private or public owned workplaces of small, medium or large size, and on each top, middle or low managerial level. An interview sample of managers was drawn by randomly selecting a number of managers from each group that reflected the equivalent relative size of the group. 404 managers were interviewed. The response rate was $70 \%$. Non-responses were most often due to not being able to reach the person under the period of data collection $(22 \%)$ or unwillingness to take part $(8 \%)$. Non-responses were equally distributed over the six groups used for selection of workplaces.

The managers were asked 15-26 questions about themselves: sex, age, which level of managerial position they held, number of directly subordinated, whether they practised any form of shared leadership in the sense of "collectively assuming responsibility with another person for a certain managerial area", formal equality in sharing or not, having responsibility in common formally or only informally, number of persons shared with and their gender, their own label on their way of sharing, the number of years in shared leadership, and, lastly, their opinion about shared leadership. The most specific questions were addressed to those who formally and equally shared. This was in line with the intention to find the frequency of the specific subform joint leadership. Due to restrictions in the interview time, the other forms were not as well covered. In order to avoid misunderstandings and hasty affirmative answers, central interview questions were accompanied by lengthy and precise clarifications. This is a result of an awareness of difficulties in conceptualising what Yankelovich (1991) frames as concepts of low maturity level. According to our experience and previous studies shared leadership is a concept of low maturity level. For example, the formal sharing of leadership (Step 2a below) was read as:

\footnotetext{
... a situation where two (or more) managers share the same position. Both are managers for the same staff. They have the overall responsibility together for the activity or the unit. Each one has the mandate to make decisions concerning all responsibility, but can have divided sub-responsibilities. Formally shared leadership means that a formal decision has been made that stipulates the two managers share leadership. As manager
} 
for activity $\mathrm{X}$, do you formally share your managerial position with another manager? (Translated excerpt from the interview questionnaire).

A weighting procedure was undertaken to make the data material representative for working life in Sweden. Based on the screening the total number of managers on each managerial level was calculated; the number of managers on each level was summed up for each of the six categories (sector resp. number of employees); finally the number of managers per category was accordingly estimated. Given the response rate for the study, the weighting means that the replies would correspond to an estimated 313,000 managers out of the 350, 000 managers. Base numbers from the weighting procedure have been used as base numbers for percentage calculations in the study; the percentages given should be treated as approximations. The size of the sample limited the extent of subdivision possible with reliability unimpaired. The weighted material is based upon a total of 404 interviewees.

Concerning background variables in the manager population in Swedish working life: 54 $\%$ were in the private sector; $46 \%$ in the public sector. In terms of workplace size: $46 \%$ were found in small workplaces, $25 \%$ in medium workplaces, and $29 \%$ in large workplaces. A total of $37 \%$ of the manager population were women.

\section{Definitions and operationalizations}

A categorisation by Härenstam (2005) was used to process the data material for the representation of industrial identity: the categorisation serves to group activities according to organisational, managerial, competence-related, and market-related similarities.

Managers were defined as persons having subordinates by reason of their position. Shared leadership was operationalized in the manager interviews in a stepwise procedure described below. Data collection was carried out through an operationalization based on the our previous understanding of shared leadership among managers in general, and designed to be able to identify also the subform of joint leadership presented in Table 1 . The first step is the least precise form and concerns those who share leadership in some way. The next step distinguished between those who share leadership by virtue of formal decisions by the organization and those who share on a parity basis in practice only. Step 3 divides those sharing formally into whether their sharing was unequal or equal in the formal hierarchical sense. Step 4 breaks the information down into the most equal forms.

Step 1. Sharing in some way: The least specific level (sharing in the broad sense). The sum of $2 a$ and $2 b$.

Step 2a. Formally sharing the managerial position: A formal decision whereby two (or more) managers share the same managerial position and the overarching responsibility for the operation or unit concerned.

Step 2b. Sharing in practice only (i.e. sharing informally): In practice, managerial responsibility is shared with one or more others (without formal decision).

Step 3a. Formally and unequally sharing: Formally sharing as a subordinate (assistant, deputy, vice etc.) or as the superior manager to the person with whom one shares. Subdivision of $2 \mathrm{a}$.

Step 3b. Formally and equally sharing: Formally sharing on an equivalent level (i.e. without any formal ranking order between the managers). Subdivision of $2 \mathrm{a}$.

Step 4. Formally sharing the same managerial position with someone else on an equivalent level (i.e. no formal ranking order between the managers), having subordinate responsibility and wholly or mainly sharing all types of work tasks together both formally and in the practical everyday context. 
Step 4 a) Joint leadership: In common and holding separate appointments (subdivision of $3 b$ ). Step 4 b) Functionally sharing: Divided and holding separate appointments (subdivision of $3 b)$.

Step 4 c) Other equal sharing: Others formally sharing the same managerial position with someone else on an equivalent level (subdivision of $3 b$ ).

\section{Results}

Results demonstrate that shared leadership occurs in all kinds of workplaces in Sweden; that is to say, in both public and private sector, in a variety of industries, on all managerial levels, and at workplaces of different sizes. A total of $41 \%$ of managers in Swedish working life were found to share their leadership in the broad sense, either in some way: formally $(15 \%)$ or in practice only $(26 \%)$; they share their managerial position with one or more others, in the sense that they state that they together assume an overarching responsibility for the operation with another person. Nearly one manager in ten $(9 \%)$ reports sharing leadership on an equal basis. $5 \%$ are concluded to practise the most far-reaching form, that of joint leadership: equally sharing in both formal and practical terms and jointly sharing both work tasks and responsibilities. (See Figure 2).

Figure 2. Overview of occurence of shared leadership 4 of shared leadership, $n=404$.

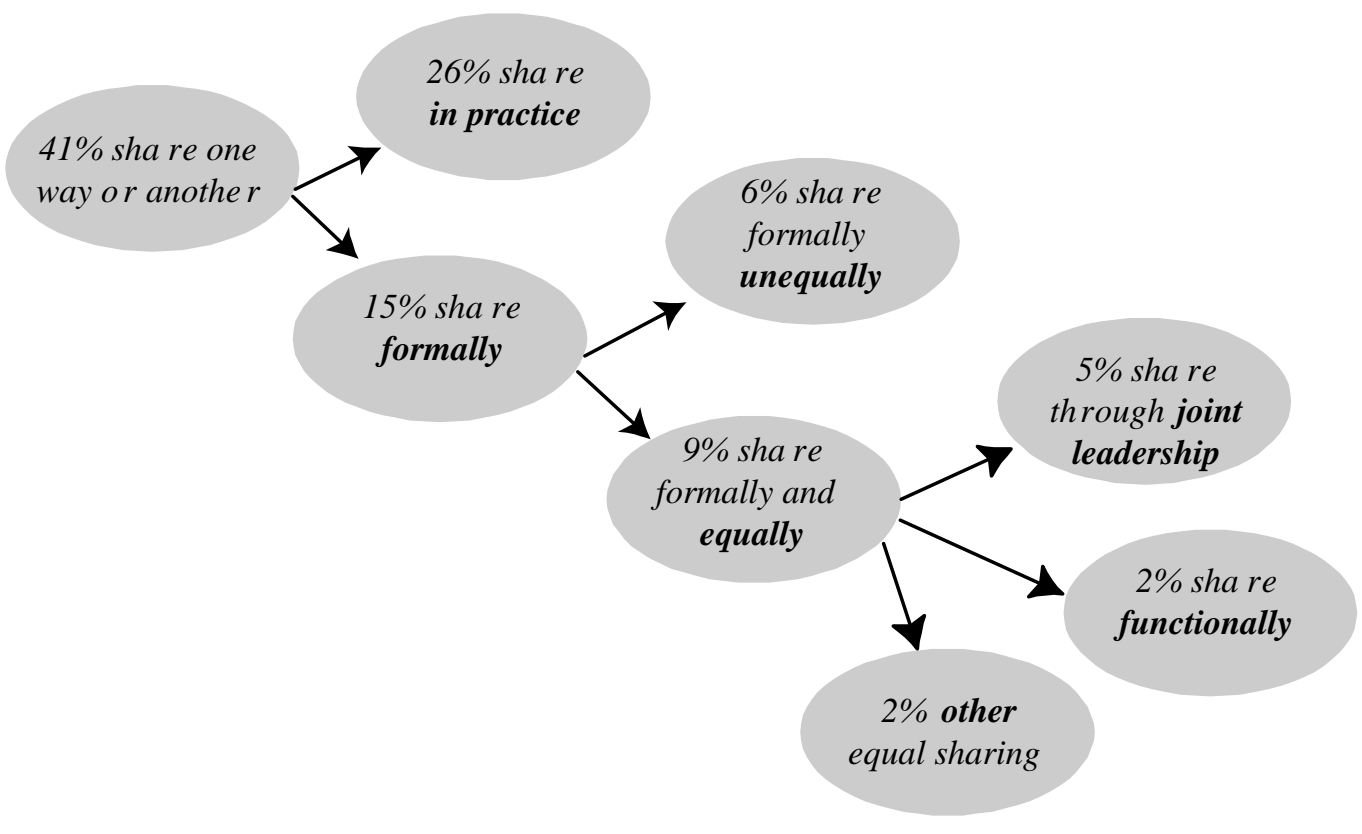

The existence of managers sharing leadership in some way is equally common in the private $(59 \%)$ and public (58 \%) sectors (Figure 3). Formal and equal sharing is more common in the public sector and on lower levels of management. Sharing, in practice only, is somewhat more common in the private sector.

${ }^{4}$ Due to time limitations for the interviews questions were not asked that would have enabled a subdivision in the figure for sharing in practice and sharing unequally. 
Figure 3. Percentage of managers in private and public sector sharing leadership by formal decision or in practice only, $n=404$.

\section{Private sector}

Not

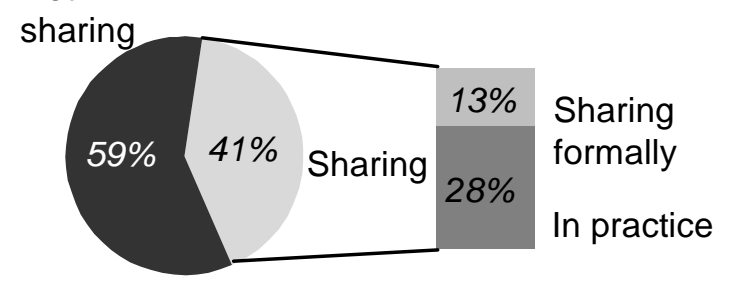

\section{Public sector}

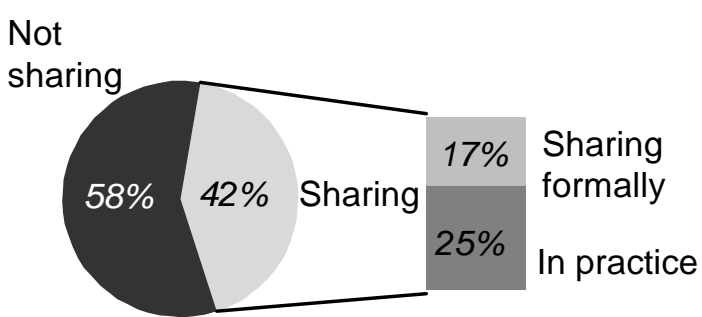

Shared leadership in the broadest sense takes place in small, medium, and large workplaces; it is particularly common in medium (46\%) sized workplaces. Formally shared leadership is most widespread in medium-sized workplaces $(28 \%)$ and so is the formally and equally shared $(15 \%)$. Sharing in small workplaces is mostly done in practice only (34\%). (See Figure 4).

Figure 4. Percentage of managers in small, medium and large workplaces sharing leadership by formal decision or in practice only, $n=404$.

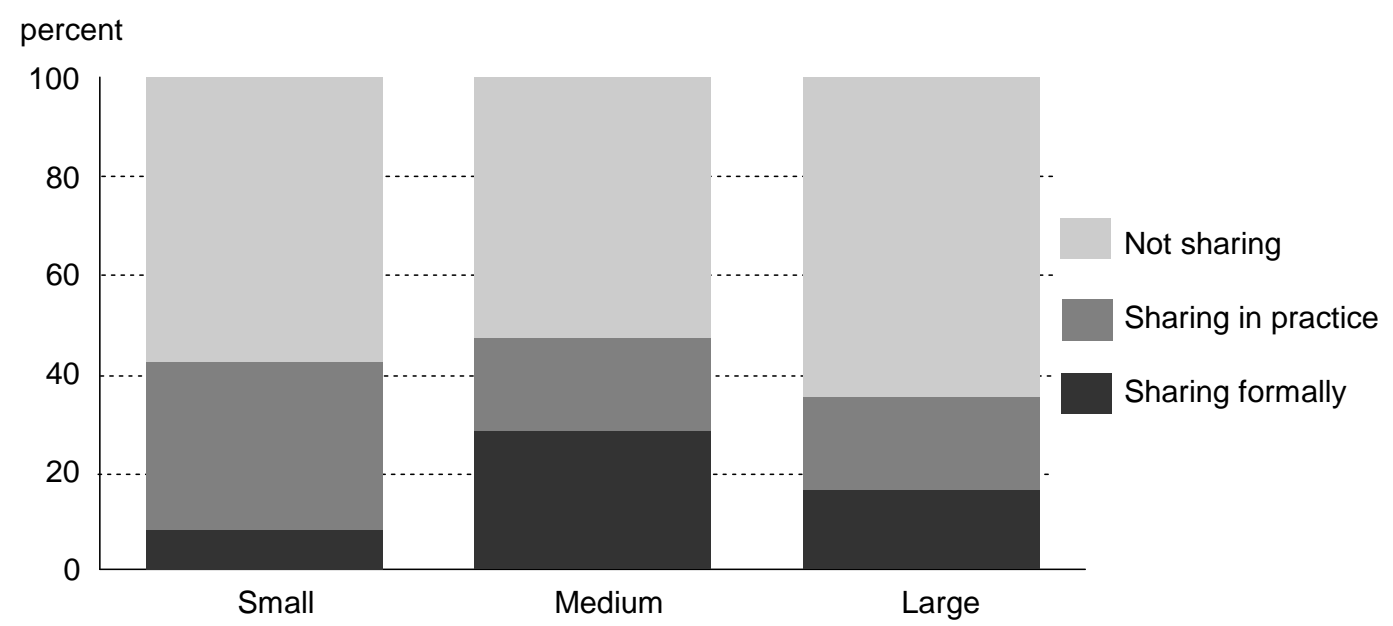

The proportion of managers sharing leadership in some way varies between industrial branches, ranging from $36 \%$ to $52 \%$. Shared leadership is most widespread in the manpower-intensive service sector that includes, for example, retail trade, goods distribution, service production, and brokerage. Formal sharing is also somewhat more widespread in manpower-intensive services. Sharing in practice, without any formal decision, is quite evenly distributed between different industrial branches. All forms of shared leadership exist on all managerial levels.

\section{Background factors and sharing constellations}

Those sharing leadership are predominantly experienced managers of various ages, with men and women $(62 \%$ and $38 \%$ ) represented approx. as in the population of managers in Sweden. Women more often than men practise shared leadership with formal decision-making powers, 
while men tend to more often share in practice only. (See Figure 5). Women also formally and equally share more often.

Figure 5. Percentage of male and female managers sharing leadership by formal decision or in practice only.

Sharing formally $(n=52)$

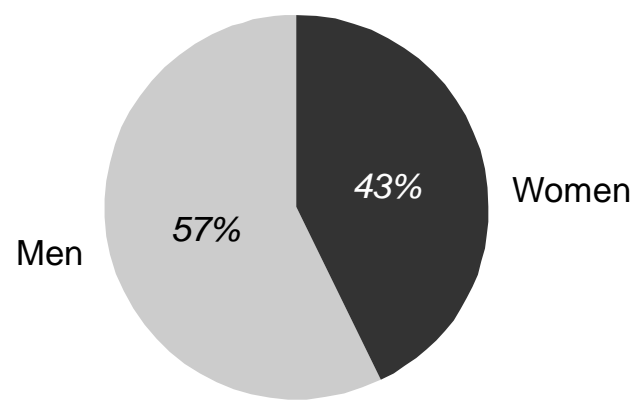

Sharing in practice $(n=96)$

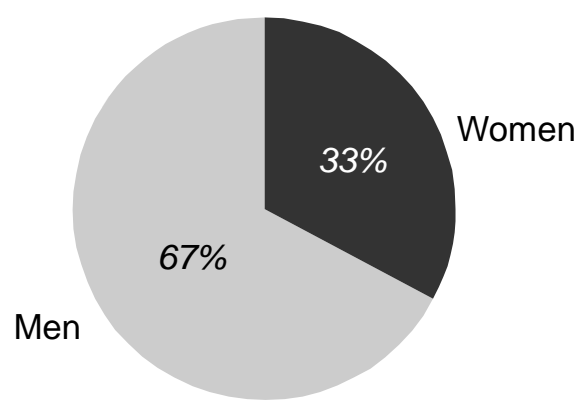

The age structure of those sharing leadership in some way roughly agrees with the age structure of the population of managers in Swedish working life. The length of time for which the managers have been practising shared leadership is four years or less for over half of those sharing in some way. Experience of shared leadership has also been relatively short among the managers who formally share, and still more so among those stating that they share in practice only.

Sharing with one person is the most common arrangement (62\%); however, almost onethird of those sharing leadership do so with more than one other person. The most common arrangement is men sharing with men. Mixed-gender constellations are second and women sharing with women come third. Furthermore, it was found frequent among sharing managers not to use any specific label for their managerial cooperation.

\section{Discussion}

Unlike several other organization and leadership trends that are brought to Sweden (mainly from the United States), shared leadership on low and middle levels of management may be described as a locally grown Swedish model (Döös \& Wilhelmson, 2003): a model that fits in with systems where organizational solutions are based upon autonomous teams, groups, and associates that are according to Sisson (2000), common in Swedish workplaces, i.e. systems in which power is delegated and shared in other respects as well. However, since the managerial sharing of leadership was before this study also invisible in Sweden - this might as well be the case in a number of other countries. The results confirm what several leadership researchers have pointed to. For example, Heenan and Bennis (1999) stated that "even the most da Vincian CEOs acknowledge that they can't do everything themselves", and O'Toole, Galbraith and Lawler (2002) called it a universal myth that leadership is singular. Despite the fact that this leadership occurrence has largely been non-existent in research literature there are business specific exceptions which include studies and theory development concerning co-principalship and distributed leadership within the education sector (e.g. Court, 2003; Eckman, 2006; Gosling, Bolden, \& Petrov, 2009; Gronn \& Hamilton, 2004), and studies of shared leadership and partnerships within health care (e.g. Casanova, 2008; Fallis \& Altimier, 2006; Rosengren \& Bondas, 2010; Steinert, Goebel, \& Rieger, 2006).

In investigating whether shared leadership can be tracked on a work-life level, this study aims to contribute knowledge about how common shared leadership is among managers in 
Sweden: both in the broad sense and, specifically, in terms of formally and equally sharing in joint leadership. Thus, a search has been made for equal assumption of responsibilities and, specifically, for a formal mandate for decision-making, both individually and together, affecting the full range of responsibilities attach to the managerial post. The results reveal that shared leadership is tracked on a work-life level and that the most far-reaching form joint leadership was found among $5 \%$ of the managers. Thus, the phenomenon cannot be ignored as merely anecdotal. This study contributes knowledge about a recent work-life phenomenon's occurrence - and so begins to fill up a knowledge gap.

The main problem during the study is connected with trying to quantify a phenomenon with low level of maturity, using Yankelovich's (1991) term for conceptual indistinctness in society. Accordingly, this study has charted a phenomenon that people (including managers in general) have not yet conceptualised. Previous studies and experiences had shown that most informants could not be expected to have a definition of shared leadership prior to the interview, which is why the straightforward question "Do you share leadership" was impossible to ask. Thanks to the research team's prior knowledge of the subject, the study made as much headway as possible in this respect. Considering the figure of $41 \%$ of managers sharing leadership in some way makes it probable that too broad a phenomenon was captured. This means that more studies are needed to get more stable percentages and that the results and methods of this study will be helpful for future research in this matter, both in Sweden and internationally.

\section{Conclusions}

The results of the current study try to explain the relevance of shared and joint leadership. This is a step to increase and develop the studies on sharing managers in general and joint leadership in particular. The study shows the relevance of shared leadership and joint leadership in that they exist to a measurable extent among managers in Swedish working life, in both public and private sector. At the onset of the study, this was not known. Thus, earlier identified examples of shared and joint leadership are not to be disregarded as isolated cases but are, instead, part of a widespread way of organizing leadership in Sweden. The results of the current study try to show how shared leadership is distributed with statistical descriptive data. As such, therefore, this is an important step in order to continue to study shared leadership deeper, and to investigate into whether this is an increasing trend, in Sweden as well as in other countries. When shared leadership is seen as a widespread practice this assumingly reflects a situation in Swedish working life where managers demand, use and allow for non-traditional ways of organizing leadership. In practice, organizations may use the knowledge that sharing of leadership is not a marginalized phenomenon and, therefore, allow for more pluralism in how leadership is organized.

In all, this study adds relevance to influencing perceptions of leadership towards a greater degree of pluralism, in which questions of leadership naturally incorporate more interactive variations than does the hitherto accepted theory of singular leadership. The time has gone by when the standard model automatically equals a managerial position to one leader. However, pluralism calls for qualified deliberation concerning when and how shared leadership - or solo leadership - is appropriate. Future research has several questions left to answer and issues to shed light upon in order to further elaborate the widespread but under-researched issue of shared leadership. 
Acknowledgements. This work was supported by VINNOVA, the Swedish Governmental Agency for Innovation Systems. The authors want to express their gratitude to the anonymous reviewers for their helpful comments on this paper.

\section{References}

Alvarez, J. L., Svejenova, S., and Vives, L. (2007) Leading in pairs, MIT Sloan Management Review, 48(4), 10-14.

Alvesson, M., and Sveningsson, S. (2003) Managers doing leadership: the extraordinarization of the mundane, Human Relations, 56(12), 1435-1459.

Bolden, R. (2011) Distributed leadership in organizations: a review of theory and research, International Journal of Management Reviews, 13, 251-269.

Casanova, J. (2008) Medical staffs and nursing staffs: the need for joint leadership, The Physician Executive, November, 24-27.

Court, M. R. (2003) Towards democratic leadership. Co-principal initiatives, International Journal of Leadership in Education, 6(2), 161-183.

Döös, M. (2007) Organizational learning. Competence-bearing relations and breakdowns of workplace relatonics, in L. Farell \& T. Fenwick (Eds.), World Year Book of Education 2007. Educating the global workforce. Knowledge, knowledge work and knowledge workers, 141-153, London: Routledge.

Döös, M. (2010) Organising leadership differently, Paper presented at the 9th International Studying Leadership Conference (ISLC), Dec 12-13 2010, Lund, Sweden.

Döös, M. and Wilhelmson, L. (2003) Shared leadership - a trend for the future? In C. von Otter (Ed.), Outside and inside Swedish working life - researchers analyze and speculate about trends in future work. Worklife in transition 2003:8, 323-344, Stockholm: National Institute for Working Life, (in Swedish).

Döös, M. and Wilhelmson, L. (2011) Collective learning: interaction and a shared action arena, Journal of Workplace Learning, 23(8), 487-500.

Döös, M., Wilhelmson, L. and Hemborg, A. (2003a) Shared leadership as a possibility, in L. Wilhelmson (Ed.), Renewal in Swedish workplaces, 182-211, Stockholm: National Institute for Working Life. (In Swedish)

Döös, M., Wilhelmson, L. and Hemborg, Å. (2003b) Contagious power - joint leadership as influence process, Ledmotiv, 3, 58-71. (In Swedish)

Eckman, E.W. (2006) Co-principals: characteristics of dual leadership teams, Leadership and Policy in Schools, 5, 89-107.

Ensley, M.D., Hmieleski, K.M. and Pearce, C.L. (2006) The importance of vertical and shared leadership within new venture top management teams: implications for the performance of startups, The Leadership Quarterly, 17(3), 217-231.

Erlingsdóttir, G. (2010) Managing change by Mumin's philosophy. Shared leadership in a primary health clinic, Paper presented at the 9th International Studying Leadership Conference (ISLC), Dec 12-13 2010, Lund, Sweden.

Fallis, K. and Altimier, L. (2006) Shared leadership: leading from the bottom up, Newborn and Infant Nursing Reviews, 6, 3-6. 
Gosling, J., Bolden, R. and Petrov, G. (2009) Distributed leadership in higher education: what does it accomplish?, Leadership, 5(3), 299-310.

Greenberg-Walt, C. L. and Robertson, A. G. (2001) The evolving role of executive leadership, in W. Bennis, G.M. Spreitzer and T.G. Cummings (eds.), The future of leadership. Today's top leadership thinkers speak to tomorrow's leaders, 139-157, San Francisco: Jossey-Bass.

Gronn, P. and Hamilton, A. (2004) A bit more life in the leadership: co-principalship as distributed leadership practice, Leadership and Policy in Schools, 3(1), 3-35.

Heenan, D. A. and Bennis, W. (1999) Co-Leaders. The power of great partnerships, New York: John Wiley \& Sons, Inc.

Hildingsson, K. and Krafft, C. (2003) High time for leadership. On support to managers, Stockholm: SACO. (In Swedish)

Holmberg, I. and Tyrstrup, M. (2010) Well then - what now? An everyday approach to managerial leadership, Leadership, 6(4), 353-372.

Holmberg, I. and Åkerblom, S. (2006) Modelling leadership - implicit leadership theories in Sweden, Scandinavian Journal of Management, 22(4), 307-329.

Holmberg, I. and Åkerblom, S. (2007) Primus inter pares. Leadership and culture in Sweden, in J. S. Chokar, F. Brodbeck \& R. J. House (Eds.), Culture and leadership around the world: The GLOBE book of in depth studies of 25 societies. New Jersey: Lawrence Erlbaum Associates, Inc.

Holmberg, K. and Söderlind, E. (2004) Leading through sharing. Shared leadership in practice, Stockholm: Navigator Dialog. (In Swedish)

Härenstam, A. (2005). Different development trends in working life and increasing occupational stress require new work environment strategies, Work, 24, 261-277.

Isaksson, P. (2008) Leading companies in a global age. Managing the Swedish way, No. VR 2008:14, Stockholm: Vinnova.

Karlsson, J. and Rubensson, C. (2001) Shared leadership. A leader duo in cooperation, Unpublished Master's Thesis, Halmstad University, Halmstad. (In Swedish)

Larsson, G., Carlstedt, L., Andersson, J., Andersson, L., Danielsson, E., Johansson, A., et al. (2003) A comprehensive system for leader evaluation and development, Leadership \& Organization Development Journal, 24(1), 16-25.

Marion, R. and Uhl-Bien, M. (2002) Complexity v. transformation: The new leadership revisited, Paper presented at the Managing the Complex IV - Conference on Complex Systems and the Management of Organizations, Ft. Meyers, Florida, USA.

O'Toole, J., Galbraith, J. and Lawler, E.E.I. (2002) When two (or more) heads are better than one: the promise and pitfalls of shared leadership, California Management Review, 44(4), 65-83.

Pearce, C.L. (2004) The future of leadership: Combining vertical and shared leadership to transform knowledge work, Academy of Management Executive, 18(1), 47-57.

Pearce, C. L. and Conger, J. A. (2003) All those years. The historical underpinnings of shared leadership, in C.L. Pearce and J.A. Conger (eds.) Shared leadership. Reframing the hows and whys of leadership, 1-18, Thousand Oaks: SAGE Publications. 
Rosengren, K. (2008) Health and medical care organisation in change - From distant to shared leadership. Jönköping University, Jönköping.

Rosengren, K. and Bondas, T. (2010) Supporting "two-getherness": assumption for nurse managers working in a shared leadership model, Intensive and Critical Care Nursing, 26, 288-295.

Sally, D. (2002) Co-leadership: lessons from republican Rome, California Management Review, 44(4), 84-99.

Sisson, K. (2000) Direct participation and the modernisation of work organisation, Dublin: European Foundation for the Improvement of Living and Working Conditions.

Sjöberg, E. (2000) Co-existence or no existence. The art of running an entrepreneurial business together, Unpublished Master's thesis, Stockholm School of Economics, Stockholm.

Steinert, T., Goebel, R. and Rieger, W. (2006) A nurse-physician co-leadership model in psychiatric hospitals: Results of a survey among leading staff members in three sites, International Journal of Mental Health Nursing, 15, 251-257.

Streatfield, P.J. (2001) The paradox of control in organizations, London: Routledge.

Thorpe, R., Gold, J. and Lawler, J. (2011) Locating distributed leadership, International Journal of Management Reviews, 13, 239-250.

Troiano, P. (1999) Sharing the throne, Management Review, 88(2), 39-43.

Wilhelmson, L. (2006) Transformative learning in joint leadership, Journal of Workplace Learning, 18(7-8), 495-507.

Wilhelmson, L. and Döös, M. (2009) Sustainable heritage in a rapidly changing environment, in P. Docherty, M. Kira and A.B. Shani (eds.) Creating sustainable work systems. Developing social sustainability, 2 ed., 117-130, London: Routledge.

Wilhelmson, L., Döös, M., Backström, T., Bellaagh, K. and Hanson, M. (2006) Perspectives on shared leadership in some municipal bodies, Work Life Report 2006:50, Stockholm: National Institute for Working Life. (In Swedish)

Vine, B., Holmes, J., Marra, M., Pfeifer, D. and Jackson, B. (2008) Exploring co-leadership talk through interactional sociolinguistics, Leadership, 4(3), 339-360.

Wistrand, E. (1978) Politics and literature in ancient Rome, 2nd ed., Göteborg: Paul Åströms förlag. (In Swedish)

Yankelovich, D. (1991) Coming to public judgement. Making democracy work in a complex world, Syracuse: Syracuse University Press.

Yukl, G. (2002) Leadership in organizations, 5th ed., Upper Saddle River, NJ: Prentice-Hall International, Inc.

Yukl, G. (2009) Leading organizational learning: reflections on theory and research, The Leadership Quarterly, 20, 49-53. 